\title{
Analysing the influence of human activity on runoff in the Weihe River basin
}

\section{CUI SHEN \& HUANG QIANG}

Key Lab of Northwest Water Resources and Environment Ecology of MOE, Xi'an University of Technology, Xi'an 710048 , China

wresh@mail.xaut.edu.cn

\begin{abstract}
Changing runoff patterns can have profound effects on the economic development of river basins. To assess the impact of human activity on runoff in the Weihe River basin, principal component analysis (PCA) was applied to a set of 17 widely used indicators of economic development to construct general combined indicators reflecting different types of human activity. Grey relational analysis suggested that the combined indicator associated with agricultural activity was most likely to have influenced the changes in runoff observed within the river basin during 1994-2011. Curve fitting was then performed to characterize the relationship between the general agricultural indicator and the measured runoff, revealing a reasonably high correlation $\left(\mathrm{R}^{2}=0.393\right)$ and an exponential relationship. Finally, a sensitivity analysis was performed to assess the influence of the 17 individual indicators on the measured runoff, confirming that indicators associated with agricultural activity had profound effects whereas those associated with urbanization had relatively little impact.
\end{abstract}

Key words Weihe River basin; principal component analysis; grey relational analysis; sensitivity analysis method; social and economic activities

\section{INTRODUCTION}

Runoff volumes are sensitive to both climate change and changing land use patterns (He et al. 2012). Consequently, there is great interest in determining how global warming interacts with other environmental changes and human activities to influence runoff behaviour and the water cycle (Hou et al. 2011). The measured runoff volumes in China's six largest river basins have declined significantly over the last 50 years; a particularly pronounced decline has occurred in the middle and lower reaches of the Yellow River, especially in the basins of the Jinghe and Weihe rivers (Zhang et al. 2007, 2009). The Weihe River basin is located in the eastern part of the fragile ecological environment of Northwest China, which is prone to natural disasters and is heavily affected by human activity, especially in the vicinity of Guanzhong. Because alterations in the region's runoff patterns could adversely affect regional development and hinder attempts to mitigate climate change, we investigated the relationship between runoff in the Weihe River basin and changes in socioeconomic activity within the basin over time.

The Weihe River flows over China's Loess Plateau, originating north of Niaoshu mountain in Weiyuan county of Gansu Province, and emptying into the Yellow River in Tongguan county of Shaanxi Province. It has a drainage area of $135000 \mathrm{~km}^{2}$, is $818 \mathrm{~km}$ long, and flows in an eastward direction through 84 counties and three provinces across the Guanzhong basin (Zhang et al. 2009). The Weihe River basin spans longitude and latitude ranges of $103.5^{\circ}-110.5^{\circ} \mathrm{E}$ and $5^{\circ}-37.5^{\circ} \mathrm{N}$, respectively. Its two main tributaries are the rivers Jinghe and Beiluohe (Jiang et al. 2013). The southeastern part of the Weihe River basin is located in the continental monsoon zone, while the northwest is in the transitional zone between arid and humid regions, which experiences droughts in spring and alternating periods of rainy heat and drought in summer due to the west Pacific Subtropical High. The region is dry and cold in the autumn and winter due to the Mongolia High (Zhang 2002). Around 65\% of the basin's annual precipitation occurs between July and October (Wang and Wang 2000). The region's average temperature is -1 to $-3^{\circ} \mathrm{C}$ in the coldest month (January) and $23-26^{\circ} \mathrm{C}$ in the warmest (July) (He and Xu 2006).

\section{DATA SOURCES AND METHODOLOGY}

\subsection{Data sources}

Socio-economic data for the Guanzhong region were obtained from the statistical yearbook of Shaanxi province (1995-2012). Measured and unimpaired runoff volumes were obtained from 


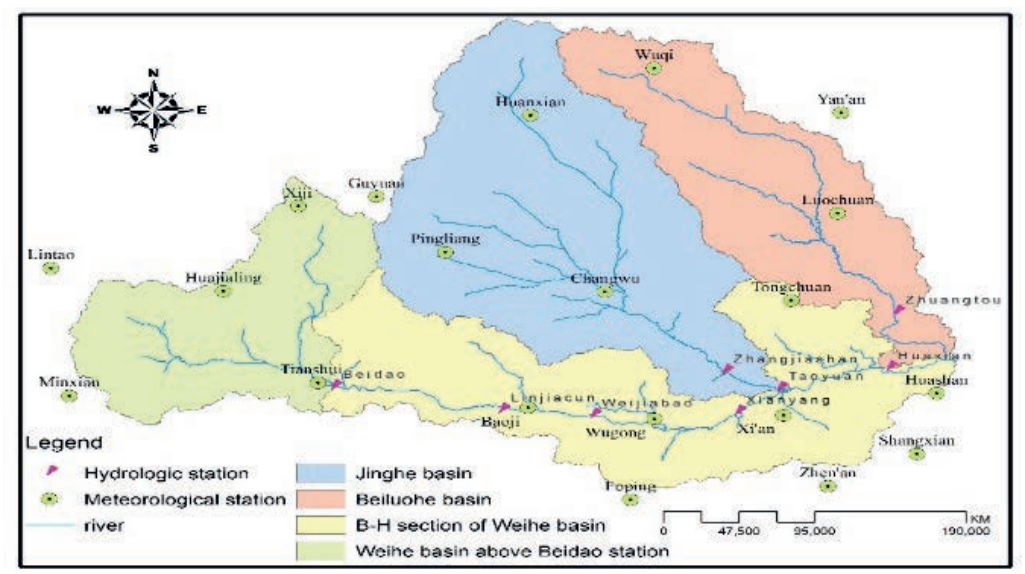

Fig. 1 The Weihe River basin

measurements made at Huaxian Station (1994-2011) and were kindly provided by the Yellow River Conservancy Commission.

\subsection{Methodology}

Principal component analysis (PCA) was used to extract principal components from a set of indicators of social and economic activity in the Guanzhong area of the Weihe River basin. Grey relational analysis was then used to determine the correlation between these principal components and the runoff data. The curve estimation feature of SPSS was used to obtain establish a regression equation relating the principal components to the measured runoff values. Finally, a sensitivity analysis was performed to determine the influence of each individual socio-economic activity indicator on the runoff volumes of the Weihe River basin.

2.2.1 Principal component analysis PCA was introduced by Pearson in 1901 and extended to random vectors in 1933 by Hotelling ( $\mathrm{Yu}$ and $\mathrm{Fu} 2005$ ). It is mainly used to reduce the dimensionality of large datasets by converting many observations of correlated variables into a set of values of linearly uncorrelated principal components, thereby simplifying subsequent data handling and interpretation (Liu and Zhang 2011). PCA was performed using SPSS as described by Lin and Zhang (2005) to construct generalized indicators reflecting different types of social and economic activity within the basin.

2.2.2 Grey relational analysis Grey relational analysis (GRA) is a component of the grey system theory developed by Prof. Deng. It aims to quantitatively describe the evolution of a studied system in comparative terms. Essentially, it is used to determine the extent to which a given sequence of observations resembles a reference sequence and to determine the correlation between the two (Zhou and Li 2007).There are two kinds of GRA, absolute and relative. Relative GRA is used to characterize the dynamic similarity of the investigated sequences and only provides information of the rate of change of the values in the sequence. However, it avoids some problems that have been identified with absolute GRA (Chen 2007). In this work, a relative GRA was performed to assess the similarity of the trends observed in the runoff data to the variation observed in the generalized socio-economic activity indicators obtained from the principal component analysis.

2.2.3 Sensitivity analysis Sensitivity analysis is used to determine how sensitive the output of a model or system is to uncertainty in its various inputs. In this work, sensitivity analysis was performed on a model relating the runoff due to human activity within the Weihe River basin to variation in one of the generalized socio-economic activity indicators derived by principal component analysis. The sensitivity analysis was performed to determine how changes in the individual socio-economic activity indicators that contribute to the generalized indicator influence the expected runoff. 


\section{RESULTS AND ANALYSIS}

\subsection{Principal component analysis of social and economic activities}

Seventeen indicators of socio-economic activity in the Weihe River basin were subjected to principal component analysis to create generalized measures of socio-economic activity in the region (Table 2).

The proportion of the total variation in the indicator data set explained by each individual principal component is shown in Table 1, along with the cumulative variation explained by each successive component. The first principal component $\left(\mathrm{PC}_{1}\right)$ explained $83 \%$ of the variation in annual precipitation, and the first two components (which both had eigenvalues of $>1$ ) together explained $92 \%$ of the variation. Thus, the first two PCs together describe the variation in the socio-economic indicators for the Guanzhong area of the Weihe River basin quite well. The coefficients of each indicator in these two principal components are shown in Table 2.

Table 1 Principal component analysis of the seventeen socioeconomic activity indicators.

\begin{tabular}{lllllll}
\hline Component & \multicolumn{2}{c}{ Initial Eigenvalues } & \multicolumn{3}{c}{ Extraction sums of squared loadings } \\
& $\begin{array}{l}\text { Eigenvalues } \\
\lambda \mathrm{i}\end{array}$ & $\begin{array}{l}\text { Proportion of } \\
\text { variation (\%) }\end{array}$ & $\begin{array}{l}\text { Cumulative } \\
\text { proportion of } \\
\text { variation (\%) }\end{array}$ & $\begin{array}{l}\text { Eigenvalues } \\
\lambda \text { i }\end{array}$ & $\begin{array}{l}\text { Proportion of } \\
\text { variation (\%) }\end{array}$ & $\begin{array}{l}\text { Cumulative } \\
\text { proportion of } \\
\text { variation (\%) }\end{array}$ \\
\hline 1 & 13.311 & 83.193 & 83.193 & 13.311 & 83.193 & 83.193 \\
2 & 1.442 & 9.014 & 92.208 & 1.442 & 9.014 & 92.208 \\
3 & 0.748 & 4.674 & 96.881 & & & \\
17 & $:$ & $:$ & $:$ & & & \\
\hline
\end{tabular}

Table 2 Coefficients of the 17 socio-economic indicators in the first two principal components.

\begin{tabular}{|c|c|c|}
\hline \multirow[t]{2}{*}{ Indicators } & \multicolumn{2}{|c|}{ Principal components } \\
\hline & $\mathrm{PC}_{1}$ & $\mathrm{PC}_{2}$ \\
\hline$X_{I}$ Total population at year-end (10 000 persons) & $\mathrm{A}_{1}: 0.888$ & $\mathrm{~B}_{1}:-0.249$ \\
\hline$X_{2}$ Area of Cultivated Land (1000 ha) & $\mathrm{A}_{2}:-0.799$ & $\mathrm{~B}_{2}: 0.514$ \\
\hline$X_{3}$ Total sown area $(1000 \mathrm{ha})$ & $\mathrm{A}_{3}:-0.370$ & $\mathrm{~B}_{3}: 0.702$ \\
\hline$X_{4}$ Total crop area $(1000 \mathrm{ha})$ & $\mathrm{A}_{4}:-0.765$ & $\mathrm{~B}_{4}: \quad 0.584$ \\
\hline$X_{5}$ Livestock inventory ( head ) & $\mathrm{A}_{5}: 0.578$ & $\mathrm{~B}_{5}:-0.503$ \\
\hline$X_{6}$ Primary industry GDP (10 000 yuan) & $\mathrm{A}_{6}: 0.979$ & $\mathrm{~B}_{6}: 0.175$ \\
\hline$X_{7}$ Secondary industry GDP (10 000 yuan) & $\mathrm{A}_{7}: 0.986$ & $\mathrm{~B}_{7}: 0.154$ \\
\hline$X_{8}$ Total power of agricultural machinery $\left(10^{4} \mathrm{kw}\right)$ & $\mathrm{A}_{8}: 0.986$ & $\mathrm{~B}_{8}:-0.078$ \\
\hline$X_{9}$ Housing construction area $\left(10^{4} \mathrm{~m}^{2}\right)$ & $\mathrm{A}_{9}: 0.898$ & $\mathrm{~B}_{9}: 0.294$ \\
\hline$X_{10}$ Fixed investments (100 million yuan) & $\mathrm{A}_{10}: 0.964$ & $\mathrm{~B}_{10}: 0.231$ \\
\hline$X_{11}$ Total retail sales of consumer goods (100 million yuan) & $\mathrm{A}_{11}: 0.989$ & $\mathrm{~B}_{11}: 0.141$ \\
\hline$X_{12}$ Per capita annual disposable income of urban households (yuan) & $\mathrm{A}_{12}: 0.989$ & $\mathrm{~B}_{12}: 0.076$ \\
\hline$X_{13}$ Per capita net income of rural residents (yuan) & $\mathrm{A}_{13}: 0.973$ & $\mathrm{~B}_{13}: 0.162$ \\
\hline$X_{14}$ Industrial energy consumption (million $\mathrm{kw} / \mathrm{h}$ ) & $\mathrm{A}_{14}: 0.989$ & $\mathrm{~B}_{14}: 0.023$ \\
\hline$X_{15}$ Residents' energy consumption (million kw $/ \mathrm{h}$ ) & $\mathrm{A}_{15}: 0.994$ & $\mathrm{~B}_{15}: 0.081$ \\
\hline$X_{16}$ Gross agricultural output (100 million yuan) & $\mathrm{A}_{16}: 0.971$ & $\mathrm{~B}_{16}: 0.204$ \\
\hline$X_{17}$ Gross industrial output (100 million yuan) & $\mathrm{A}_{17}: 0.969$ & $\mathrm{~B}_{17}: 0.229$ \\
\hline
\end{tabular}

Most of the indicators with positive coefficients in $\mathrm{PC}_{1}$ are measures of economic development, such as residential and industrial energy consumption or total retail sales of consumer goods. Conversely, most of the indicators with negative coefficients in $\mathrm{PC}_{1}$ are measures of agricultural development such as the region's total sown and total crop areas, and total area of cultivated land. We can thus identify $\mathrm{PC}_{1}$ as a combined economic development indicator. Similarly, the second principal component $\left(\mathrm{PC}_{2}\right)$ can be described as a combined agricultural development indicator. $\mathrm{PC}_{1}$ and $\mathrm{PC}_{2}$ were defined as follows:

$$
\begin{aligned}
& P C_{1}=A_{1} \times X_{1}+A_{2} \times X_{2}+\cdots+A_{17} \times X_{17} \\
& P C_{2}=B_{1} \times X_{1}+B_{2} \times X_{2}+\cdots+B_{17} \times X_{17}
\end{aligned}
$$




\subsection{Grey relational analysis of PCs and runoff}

To assess the impact of human activity on runoff in the Weihe River basin, we examined runoff measurements made at the Huaxian monitoring station. The difference between the unimpaired runoff $Q_{H, T}$ and the measured runoff $Q_{H, S}$ was computed to determine the runoff due to human activity, $Q_{H, R}$, in the years 1994-2011, and equations (1) and (2) were used to compute values for $\mathrm{PC}_{1}$ and $\mathrm{PC}_{2}$ over the same period. GRA was then used to assess the relationship between $Q_{H, R}$ and the two principal components. The $\gamma$ values for $\mathrm{PC}_{1}$ and $\mathrm{PC}_{2}$ were $\gamma_{1}=0.50$ and $\gamma_{2}=0.889$, respectively, indicating that the variation in $Q_{H, R}$ most closely resembles that of $\mathrm{PC}_{2}$.

\subsection{Curve fitting}

The curve estimation module of the SPSS software package was used to analyse the relationship between $Q_{H, R}$ and $\mathrm{PC}_{2}$. The best fit was achieved with an exponential relationship (Table 3). The regression analysis yielded the following relationship:

$$
Q_{H, R}=16.287 \times e^{0.083 \times P C_{2}}
$$

Figure 2 depicts an increasing function, suggesting that as the agricultural development of the Weihe River basin proceeds, human activity will cause progressively more pronounced changes in the basin's runoff.

Table 3 Results of the curve fitting analysis.

\begin{tabular}{llllllll}
\hline Formula & $\mathrm{R}^{2}$ & $\mathrm{~F}$ & $\mathrm{df}_{1}$ & $\mathrm{df}_{2}$ & Sig. & Constant & $\mathrm{b}_{1}$ \\
\hline Exponential & 0.393 & 9.706 & 1 & 15 & 0.007 & 16.287 & 0.083 \\
\hline
\end{tabular}

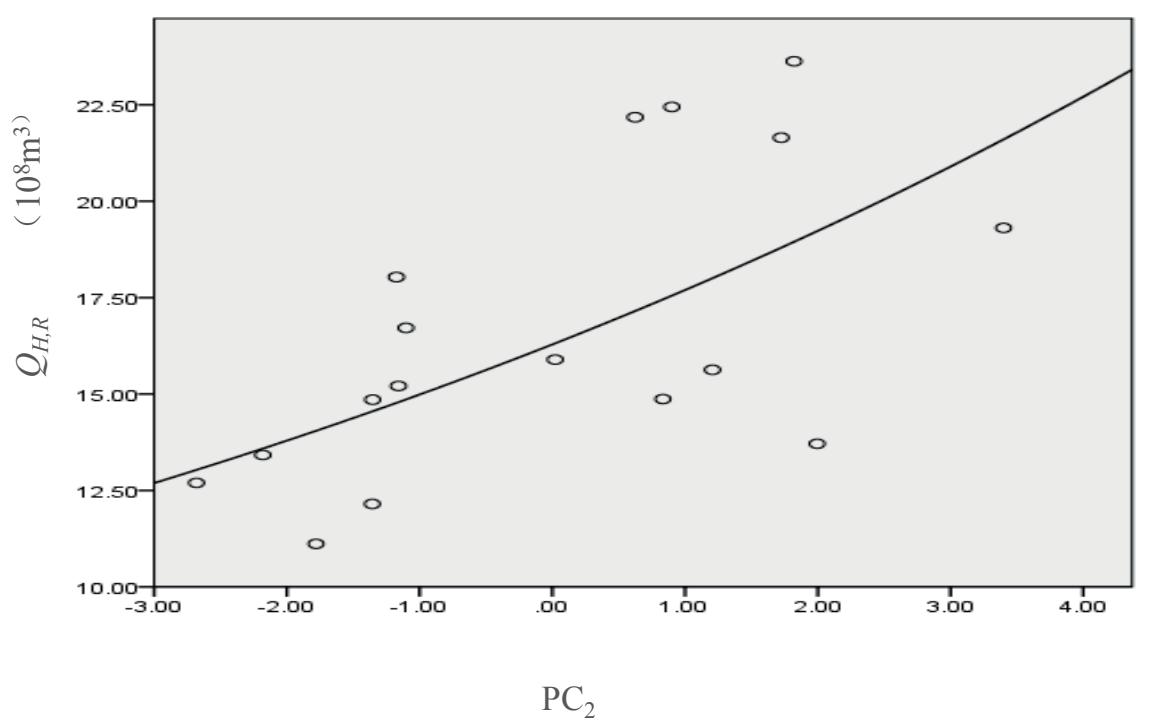

Fig. 2 The relationship between $\mathrm{PC}_{2}$ and $Q_{H, R}$. The solid line shows the fitted curve.

\subsection{Sensitivity analysis of social and economic activities and runoff}

Sensitivity analysis was performed to assess the influence of changes in specific social and economic activity indicators on $\mathrm{PC}_{2}$ and $Q_{H, R}$. Because equation (3) is nonlinear, the selection of the reference year influenced the results of the sensitivity analysis for $Q_{H, R}$. Arbitrarily, 2011 was selected as the reference year in the analysis. A tornado diagram showing the relative impact of a $1 \%$ increase in each of the 17 socioeconomic activity indicators on $Q_{H, R}$ is shown in Fig. 3.

Most of the individual indicators (with the exception of $X_{1}, X_{5}$, and $X_{8}$ ) caused $Q_{H, R}$ to increase when their value was increased by $1 \%$, The most influential indicators were $X_{3}, X_{4}$ and $X_{2}$, which caused $Q_{H, R}$ to rise by $0.23 \%, 0.16 \%$ and $0.12 \%$, respectively, when increased by $1 \%$. The most 


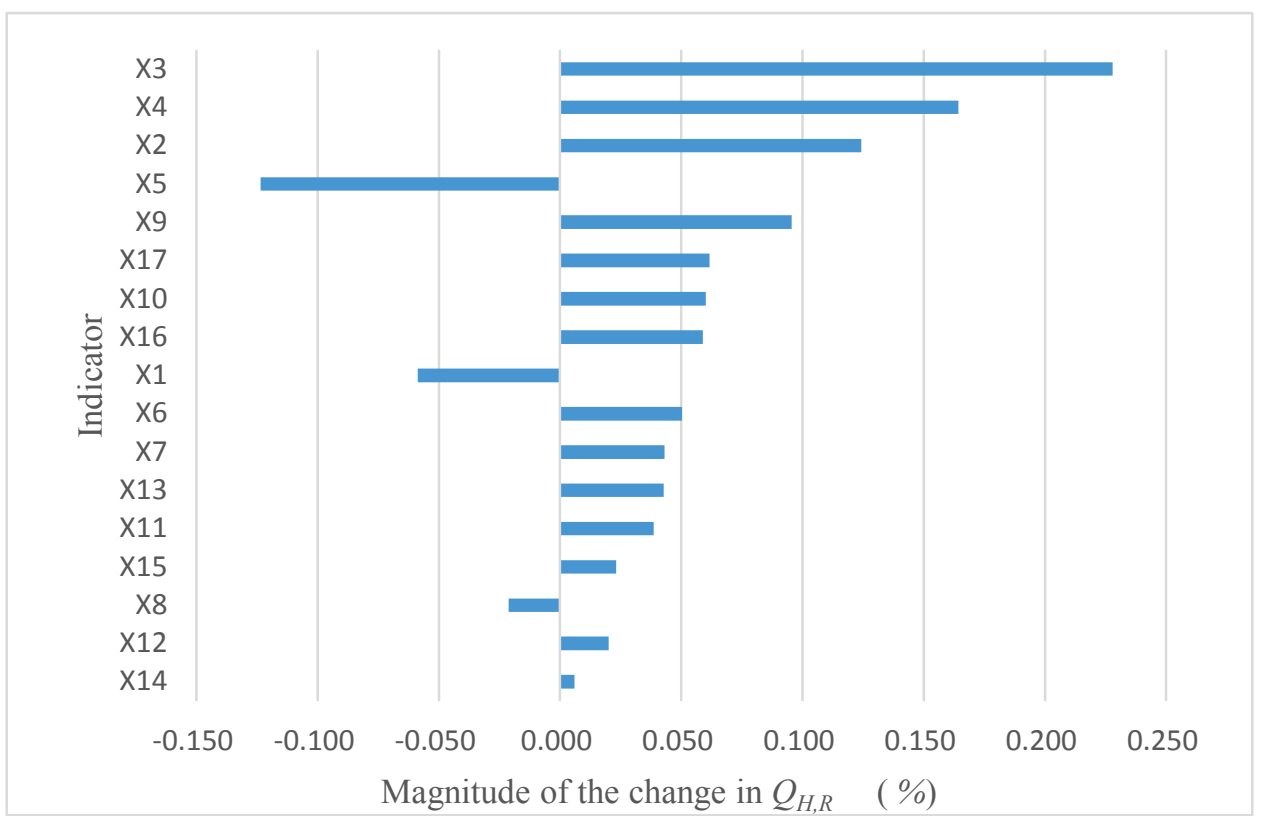

Fig. 3 Tornado diagram showing the sensitivity of $Q_{H, R}$ to a $1 \%$ increase in each of the 17 individual socioeconomic activity indicators considered in this work.

influential factor with a negative impact on $Q_{H, R}$ was $X_{5}$. Six indicators $\left(X_{9}, X_{17}, X_{10}, X_{16}, X_{1}\right)$ had modest impacts, causing $Q_{H, R}$ to change by $0.05-0.1 \%$. The other indicators all changed $Q_{H, R}$ by less than $0.05 \%$. The indicators associated with the most pronounced changes in $Q_{H, R}$ were all linked to agricultural activity, demonstrating that agriculture continues to account for most of the water use in the Weihe River basin and has profound effects on the basin's runoff as well as the demand for water resources. Indicators associated with urbanization have relatively little impact on runoff.

\section{CONCLUSIONS}

Principal component analysis (PCA) has been used to construct combined indicators of human social and economic activity in the vicinity of Guangzhong in the Weihe River basin from a set of 17 individual indicators. Relative GRA was then used to determine which of these combined indicators had the greatest effect on the runoff due to human activity $\left(Q_{H, R}\right)$. Finally, curve fitting and sensitivity analysis were used to determine which of the original 17 indicators had the greatest impact on the impact of these combined indicators on $Q_{H, R}$. It was found that most of the variation in the 17 socioeconomic activity indicators could be summarized using only two principal components: $\mathrm{PC}_{1}$, which was interpreted as a general economic development indicator, and the general agricultural development indicator $\mathrm{PC}_{2}$. Relative GRA revealed that the variation in $Q_{H, R}$ resembled that of $\mathrm{PC}_{2}$ $\left(\gamma_{2}=0.889\right)$ more closely than that of PC $_{1}$. Curve fitting using SPSS was used to derive an exponential expression relating $Q_{H, R}$ and $\mathrm{PC}_{2}$, and sensitivity analysis was then performed to identify the individual socio-economic activity indicators with the greatest effect on $Q_{H, R}$. Overall, our results indicate that agriculture has profound effects on runoff in the Weihe River basin, but the impact of urbanization on runoff is less clear.

Acknowledgements This work was financially supported by the Natural Science Foundation of China (grant nos. 51190093, 51179148, 51179149), and the National Key Basic Research 973 of China (grant no. 2012CB417003). Constructive comments from reviewers of a previous version of the paper are gratefully acknowledged. 


\section{REFERENCES}

Chen, K. (2007) Grey Correlation Analysis on Real Estate Investment and Financing in Chongqing. The Journal of Traffic University of Chongqing 7(2), 63-67.

He, W.L. and Xu, Z.X. (2006) Spatial and temporal characteristics of the long-term trend for temperature and pan evaporation in the Wei River Basin. Journal of Beijing Normal University (Natural Science) 42(1), 102-106.

He, X., Zhang, B. and Sun, L.W. (2012) Contribution rates of climate change and human activity on the runoff in upper and middle reaches of Heihe River basin. Chinese Journal of Ecology 31(11), 2884-2890.

Hou, Q.L., Bai, H.Y. and Ren, Y.Y. (2011) Analysis of variation in runoff of the main stream of the Weihe River and related driving forces over the last 50 years. Resources Science 33(8), 1505-1512

Jiang, C., Wang, F. and Mu, X.M. (2013) Effect of climate change on net primary productivity (NPP) of natural vegetation in Wei river basin (II). NPP of natural vegetation in Wei river basin. Journal of Arid Land Resources and Environment 27(5), 53-57.

Lin, H.M. and Zhang, W.L. (2005) Similarities and differences of principal component analysis and factor analysis and SPSS software. Statistics Research 2005(3), 65-69c

Liu, T.T. and Zhang, H. (2011) Compared with Principal Component Analysis and Empirical Orthogonal Function Decomposition. Statistics and Decision 340(16), 159-162

Wang, G.Q. and Wang, Y.Z. (2000) Analysis on Causes of Runoff and Sediment Variation in Weihe Basin Based on Hydrological Model. Journal of Soil Water Conservation 2000(4), 22-25.

Yu, X. F. and Fu, D. (2005) Evaluation Methods of comprehensive multi-index. Statistics and Decision 2005(11), 119-121.

Zhang, J.Y., Zhang, S.L. and Wang, J.X. (2007) Study on runoff trends of six larger basins in China over the past 50 years. Advances in Water Science 18(2), 230-234

Zhang, Q., Zhang, C.J. and Bai, H.Z. (2009) New Development of Climate Change in Northwest China and Its Impact on Arid Environment. Journal of Arid Meteorology 28(1), 1-7

Zhang, Y.L. (2002) Hydrologic feature analysis for Weihe basin in Shaanxi province. Northwest Water Resources \& Water Engineering 2002(2), 62-64.

Zhang, Y.X., Wang, F. and Mu, X.M. (2009) Research of quantitative relations between Geographical environment factor and water and sediment in the Weihe River basin. Journal of Northwest A \& F University (Natural Science Edition) 37(1), 61-65.

Zhou, Q.W. and Li, H.M. (2007) The application of Grey System Theory to regional industrial structure adjustment. The Journal of Xi-an Architecture and Technology University (Natural Science) 39(3), 437-440. 